\begin{tabular}{|c|c|c|}
\hline 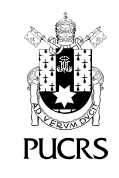 & $\begin{array}{l}\text { ESCOLA DE } \\
\text { HUMANIDADES }\end{array}$ & $\begin{array}{l}\text { Revista Digital do Programa de Pós-Graduação em Letras da PUCRS } \\
\text { Letrônica, Porto Alegre, v. 13, n. 1, p. 1-14, jan.-mar. } 2020 \\
\text { e-ISSN: 1984-4301 }\end{array}$ \\
\hline def $\mathrm{http}: / / \mathrm{dx}$ & $\mathrm{rg} / \mathbf{1 0 . 1 5 4 4 8 / 1 9 8 4 - 4 3 0 1 . 2 0 2 0 . 1 . 3 4 9 7 5}$ & \\
\hline
\end{tabular}

\title{
Alfonsina Storni, uma mulher de voz poderosa na poesia latino-americana
}

\author{
Alfonsina Storni, a woman with a powerful voice in Latin American poetry \\ Alfonsina Storni, una mujer de voz poderosa en la poesía latinoamericana
}

\author{
Hugo Jesús Correa \\ Retamar $^{1}$ \\ orcid.org/0000-0002-6849-2932 \\ hugo.retamar@ufrgs.br.
}

Recebido em: 24 jul. 2019.

Aprovado em: 18 nov. 2019.

Publicado em: 7 abr. 2020.

\section{(c) (i)}

Artigo está licenciado sob forma de uma licença Creative Commons Atribuição 4.0 Internacional.
Resumo: Este trabalho, que integra um estudo mais amplo sobre a obra de Alfonsina Storni (RETAMAR, 2004), busca evidenciar a denúncia presente em seus versos sobre o silenciamento sofrido pela mulher latino-americana de principios do século XX. Para tal, foram selecionados 14 poemas pertencentes à Antología Poética (STORNI, 1956) organizada pela autora. A seleção teve como critério os poemas que demonstravam, mais nitidamente, o engajamento da poeta contra a injustiça social vivenciada pelas mulheres de sua época. A análise se fundamenta no estudo de cada poema, na sua relação com o conjunto da obra e com a biografia da poeta. Também foi levada em conta a fortuna crítica sobre Storni. A análise demonstra que a obra de Alfonsina, além de contextualizar socioculturalmente o papel da mulher latino-americana de sua época, reivindica a liberdade para essa mulher ao demonstrar a hipocrisia da sociedade patriarcal que a condena e a silencia. Portanto, o presente estudo entende que a recuperação da obra de Storni é fundamental para os estudos contemporâneos, não apenas sobre gênero, mas sobre história, literatura e sociedade do século $X X$, pois promove um olhar critico e propulsor de mudanças sociais em favor da igualdade entre mulheres e homens. Palavras-chave: Literatura latino-americana. Mulher. Gênero. Poesia. Alfonsina Storni.

Abstract: This paper, which is part of a broader study of the work of Alfonsina Storni (RETAMAR, 2004), highlights the criticism in her verses about the silencing endured by Latin American women at the beginning of the 2oth century. To this end, 14 poems from the Antologia Poética organized by the author were selected (STORNI, 1956). The selection had as criteria the poems that most clearly depicted the poet's commitment against the social injustice faced by women of her time. The analysis is based on the study of each poem, its relationship with the work as a whole and with the poet's biography. The critical resources about Storni were also taken into account. The analysis shows that Alfonsina's work not only contextualizes the role of the Latin American woman of her time socioculturally but also claims for her freedom by revealing the hypocrisy of the patriarchal society that sentences and silences her. Therefore, this study understands that the retrieval of Storni's work is essential for contemporary studies not only on gender but on history. literature and the 2oth century society since it promotes a critical and provocative perspective of social changes on behalf of the equality between women and men. Keywords: Latin American literature. Woman. Gender. Poetry. Alfonsina Storni.

Resumen: Este trabajo, que integra un estudio más amplio sobre la obra de Alfonsina Storni (RETAMAR, 2004), busca evidenciar la denuncia presente en sus versos sobre el silenciamiento protagonizado por la mujer latinoamericana de principios del siglo XX. Para tal, seleccioné 14 poemas pertenecientes a la Antología Poética (STORNI, 1956) organizada por la propia autora. La selección tuvo como criterio los poemas que demostraban, más nítidamente, el comprometimiento de la poeta en contra de la injusticia social vivida por las mujeres de su generación. El análisis se fundamenta en la exégesis de cada poema seleccionado y en su relación con el conjunto de la obra de Alfonsina, con su biografía y con la fortuna crítica sobre la poeta. El análisis busca evidenciar que la obra de Storni, además de contextualizar socioculturalmente el papel de la 
mujer latinoamericana de su época, al demostrar la hipocresia de la sociedad patriarcal que la condena e la silencia, reivindica la libertad para esa mujer. Así, el presente estudio entiende que la obra de Storni es fundamental para los estudios contemporáneos, no solo sobre género, sino también sobre la historia, la literatura y la sociedad del siglo $X X$, puesto que recuperar la figura de la poeta puede promover una mirada crítica y propulsora de cambios sociales en favor de la igualdad entre mujeres y hombre.

Palabras clave: Literatura latino-americana. Mujer. Género. Poesía. Alfonsina Storni.

"Se pudermos examinar cuidadosamente a história do mundo, veremos que sempre foi dificil deixar a mulher falar com autonomia, com uma voz própria". 2 (Márcia Navarro)

\section{Muito prazer, Alfonsina Storni}

Alfonsina Storni surge na literatura latinoamericana como uma onda de renovação em plena Argentina do início do século XX. Desde os seus primeiros versos, Storni revela ser uma alma dolorida e sedenta de vida, exposta à crítica de uma sociedade patriarcal, fechada e cruel com uma mulher que quer, que sente e que, sobretudo, fala por meio da palavra escrita e duradoura.

A sua aparência frágil - pequena, de olhos azulados, de cabelo grisalho com fios de ouro que emolduravam um rosto extremamente jovem, segundo testemunho de seus contemporâneos (OROSCO, 1940) - contraria a sua personalidade, a sua inteligência e a sua força de mulher viva, apaixonada pela vida e pela morte, mas também, e sobretudo, pela liberdade.

Os pais da poeta eram imigrantes suiços de origem italiana que migraram para a Argentina e se estabeleceram na província de San Juan. Contudo, em 1891, devido a problemas de saúde com Alfonso Storni, pai de Alfonsina, a família regressa à Suiça já tendo dois filhos argentinos. Desse modo, a primeira poeta de valor reconhecido na América Latina, segundo Etchenique (1958), Orosco (1940) e Giordano (2009), não nasce na Argentina, mas em Sala Capriasca, um povoado da Suiça italiana, no dia 29 de maio de 1892.
Somente quando a menina completa quatro anos é que a sua familia retorna à Argentina. Entretanto, da época suiça pouco se lembrava a poeta, que se considerava argentina, fato que a levou a se naturalizar oficialmente em 1920.

Criada em San Juan, desde pequena a poeta da América Latina tinha um impulso à liberdade diferente ao das demais meninas de sua idade. Quando criança era esperta, criativa e vivia de imaginações e invenções, adorava criar histórias. Quando tinha onze anos, os pais da menina imaginativa passaram por dificuldades econômicas e ela teve que começar a trabalhar em um escritório para ajudá-los. Juntamente com a adolescência e com o trabalho, vieram a intuição poética e as primeiras poesias que já falavam de cemitérios e de mortes, como ela mesma relata em uma conferência dada em Montevidéu, em 1938. Durante a juventude, a jovem passa a trabalhar ainda no teatro de José Tallaví, acompanhando-o em uma de suas turnês pela Argentina, fato que foi considerado um grande escândalo para a época.

Após o falecimento de seu pai, ainda muito jovem, Alfonsina entra para a Escola Normal de Coronda, em Rosário de Santa Fé. Nessa época, ela mora em uma pensão e, para honrar os seus gastos, começa a cantar em segredo aos sábados e aos domingos em um teatro de bairro de Rosário, transgredindo as regras impostas à mulher da época e estando à mercê dos comentários provincianos a respeito de sua conduta. A falta de liberdade e a má fé das pessoas de Rosário corrompem e entristecem a jovem e ela vê, como nos poemas que já fazia desde a adolescência, a morte como uma saída e como caminho para a liberdade. Diz Alfonsina, depois do ocorrido em Rosário: "Después de lo sucedido he resuelto eliminarme. Adiós" (STORNI apud OROSCO, 1940, p. 86).

A esses acontecimentos, viriam se juntar outros tantos, escandalosos para a época e incompreendidos pela sociedade, na biografia de Alfonsina Storni. Entre eles, o nascimento 
de um filho ilegítimo, fato que a fez partir para Buenos Aires, levando debaixo do braço apenas livros de Rubén Dario e poucas roupas. Assim, a já "mulher", Alfonsina, viaja com os seus livros, o seu filho e as suas ânsias a buscar alento, consolo e compreensão em uma cidade grande e em expansão como era a capital da Argentina da época. Contudo, na capital, ela não consegue emprego de professora e trabalha em uma casa de comércio, lugar de onde saem os seus primeiros versos publicados em 1916, como confessa:

Clavada en mi sillón, al lado de un horrible aparato para imprimir discos, dictando órdenes y correspondencias a la mecanógrafa, escribo mi primer libro de versos. iDios te libre amigo mío, de La inquietud del rosal!...Pero escribí para no morir (STORNI, 1938, apud OROSCO, 1940, p. 254).

Essa declaração, que mostra um pouco da relação entre Alfonsina e os seus escritos, foi dada pela poeta em sua última conferência de 1938 , em Montevidéu, quando estiveram reunidas as maiores expressões femininas da literatura da América Hispânica, a saber: a uruguaia Juana de Ibarbourou; a chilena Gabriela Mistral; e, claro, Storni. Quando diz que, "escribia para no morir", Alfonsina nos desvenda as dores de sua alma de poeta. Quer dizer, faz visivel a sua triste realidade de incompreensão e revela que os seus versos the dão a oportunidade de partir a uma realidade diferente da crueldade dos "Cuadrados y ángulos", da cidade grande e do "Hombre pequenito"3 que a oprime. Portanto, escrever parece ser, para Alfonsina, a outra opção, que não a morte, de se redimir não ao mundo, mas do mundo. Logo, poeta e eu-lírico se misturam nos versos de Alfonsina Storni, já que a autora assume que escrever serve para the fazer o mundo menos pesado, materializar um mundo diferente, esvaziar a alma.

\section{A voz e a palavra de uma mulher latino- americana e poeta}

O primeiro livro de Alfonsina - La inquietud del rosal - foi o pontapé inicial para o seu legado. Alfonsina não tinha orgulho desse livro por considerá-lo inferior e poeticamente imaturo. Por outro lado, na Antología Poética (STORNI, 1956), feita por ela própria no ano de sua morte e de onde saem os poemas que aqui serão analisados, a poeta inclui como primeiro poema, não outro, senão aquele que intitula o seu primeiro livro, ou seja, "La inquietud del rosal". Vejamos:

$$
\begin{aligned}
& \text { El rosal en su inquieto modo de florecer } \\
& \text { va quemando la savia que alimenta su ser. } \\
& \text { iFijaos en las rosas que caen del rosal: } \\
& \text { Tantas son que la planta morirá de este mal! } \\
& \text { El rosal no es adulto y su vida impaciente } \\
& \text { se consume al dar flores precipitadamente } \\
& \text { (STORNI, 1956, p. 9). }
\end{aligned}
$$

Nesse livro, "imaturo" segundo a poeta, já vemos uma Alfonsina inquieta. Ela é a roseira que tem ânsia de viver, que tem uma quantidade enorme de seiva que alimenta, mas que não the dá a vida doce com a qual sonha, a qual deseja. A roseira que quer vida a consome nos pesares de seus brotos não colhidos. As rosas, então, caem da roseira, ninguém as colhe, ninguém se deleita com elas e são tantas que apodrecem a planta inteira. A roseira, assim como a alma da poeta, ainda não é adulta e, por isso, é impaciente, inquieta como o mar que vai e vem inconstante, consome-se em suas ânsias, em suas promessas de vida que acabam trazendo-lhe a morte prematura. Alfonsina chega a Buenos Aires como a própria roseira, inquieta e impaciente buscando consolo e salvação para as suas dores, e não os encontra na sociedade dura e áspera como o concreto da cidade grande. Como vemos, já desde esse primeiro livro, a poeta se aproxima da natureza doce, espelho de sua alma, que ainda não é quadrada como a cidade

A obra La inquietud del rosal trouxe à Argentina um sopro de renovação no âmbito literário, pois os versos de Alfonsina traziam temas novos escritos em espanhol, ao contrário do que faziam muitas poetas de sua época, que preferiam o francês. $\mathrm{O}$ livro foi objeto de severas criticas, segundo Helena Percas (1958), mas também de excessivos elogios.

3 As duas marcações com aspas são títulos de poemas que serão analisados na seguinte seção. 
Fato que abriu à autora as portas de revistas, editoras e semanários, com os quais começou a colaborar com o pseudônimo de Tao $\mathrm{LaO}^{4}$.

O seu primeiro livro não apenas the abre os caminhos a jornais e a revistas, mas também the abre as portas da intelectualidade portenha. A partir dele, poetas, escritores e letrados passam a ter uma mulher como companhia em seus saraus poéticos, novamente um fato incomum para a época. Essa mulher, nova nos saraus, segundo relatos da intelectualidade que lhe era contemporânea, portava-se timidamente. Era calada, não era fisicamente atrativa, era discreta, muitas vezes parecendo não estar presente, segundo relata Manuel Ugarte (UGARTE, 1938 apud PERCAS, 1958, p. 88). Mas, pouco a pouco, à medida que começa a se acostumar aos encontros, essa mesma mulher toma a palavra e se transforma em um ser divino envolto em luz. Segundo Roberto Giusti, nesses momentos, a poeta demonstrava "un extraño dominio de los temas que pasaban sobre el tapete, desconcertando al modesto auditorio con sus juicios certeros y sus frases paradojales" (GIUSTI, 1938 apud PERCAS, 1958, p. 88).

Desse modo, Alfonsina Storni se transforma aos poucos em uma promessa da poesia feminina argentina não apenas por seus versos, mas também por sua personalidade independente. Contam os seus amigos que ela era extremamente inteligente e não tão culta como se supunha, posto que não tinha muita leitura, mas sabia como poucos argumentar e envolver aos ouvintes com a perspicácia de suas palavras.

Em 1918, a promessa da poesia feminina publica o seu segundo livro El dulce daño. A crítica atribui a essa segunda obra, uma maior maturidade da poeta. Nela, Alfonsina demonstra como nunca a sede de amor e de vida que povoa a sua alma doída de mulher incompreendida, de mulher que sente. O primeiro poema do livro revela o momento de Alfonsina, desvelando-nos a fonte de sua inspiração, como sempre a alma que sofre pelo amor e que o busca constantemente. No poema "Asi" (STORNI, 1956), a vida é sofrimento e a poeta está à espera de um novo despertar, já que, ao fazer os versos ela "sueña"'.
Hice el libro asi:
Gimiendo, llorando, soñando, ay de mí.
Mariposa triste, leona cruel,
Di luces y sombra todo en una vez.
Cuando fui leona nunca recordé
Cómo pude un día mariposa ser.
Cuando mariposa jamás me pensé
Que pudiera un dia zarpar o morder.
Encogida a ratos y a saltos después
Sangraron mi vida y a sangre maté.
Sé que, ya paloma, pesado ciprés.
O mata florida, lloré y más lloré.
Ya probando sales, ya probando miel,
Los ojos lloraron a más no poder.
Da entonces lo mismo, que lo he visto bien,
Ser rosa o espina, ser néctar o hiel.
Asi voy a curvas con mi mala sed
Podandojardines de todojaez (STORNI, 1956, p. 15).

A poeta nos revela que busca o amor verdadeiro e para encontrá-lo, metamorfoseiase em borboleta, em leoa, sem ter sucesso em seu projeto. Porém, percebe que é a mesma coisa ser a "mariposa" bela, alegre, talvez, passiva e breve ou ser a "leona" forte, impetuosa, ativa e poderosa. Quer dizer, "dar luces o sombras" é indiferente para alguém que não acha o amor e o seu lugar no mundo. Nesses versos, Alfonsina evidencia a sua condição dupla de fragilidade e força quando assume ter sido borboleta, e se ter transformado e deixado levar pela vida, e ter sido leoa e ter tomado a vida pelas rédeas. Tudo isso não importa - "mariposa" ou "leona" já que da mesma forma the sangraram a vida. É como se ela estivesse fadada ao fracasso e, por esse medo de fracassar, buscasse o amor em qualquer um para acalmar as dores que a vida, que sangra, causa-lhe. Storni em "Asi" é outra vez como a roseira que se consome. Desperdiça o

4 Segundo o poeta Arturo Capvedila, Tao em chinês significa "caminho", ou lei e razão, já o adjetivo Lao significaria "antigo"; porém ele diz que acha difícil que Alfonsina soubesse o sentido das palavras antes de adotar o pseudônimo (CAPVEDILA apud PERCAS, 1958, p. 87). 
seu amor com sua sede ruim e poda "jardines de todo jaez". Ama sem restrições e deixa que o amor a transforme, fator que a leva à frustração. Que faz, então, quando já é "paloma" tranquila e madura? Geme, chora, sonha e libera os seus desejos insatisfeitos através da escrita.

De igual forma, a maltratada a poeta como podemos ver no poema "Este grave daño" que faz parte do mesmo livro El dulce daño (STORNI, 1956):

Este grave daño que me da la vida

Es un dulce daño, porque la partida

Que debe alejarme de la misma vida

Más cerca tendré.

Yo llevo las manos brotadas de rosas,

Pero están libando tantas mariposas

Que cuando por secas se acaben mis rosas

Ay, me secaré (STORNI, 1956, p. 15).

A vida é dor, mas não dói por ser ruim, e sim porque a poeta tem muita sede de vida e não consegue matar toda essa sede, o que a faz consumir-se em prantos. No poema, percebese que, ao contrário da vida, a morte para ela é a liberação, é o que vai afastá-la da dor de viver que é não saciar a sua sede de amor, a sua sede de liberdade. A morte espreita Alfonsina, já que a quantidade e a intensidade do sofrimento transformam o ato de morrer em uma condição desejada. Quando diz que traz "las manos brotadas de rosas", a poeta assume o seu desejo de amor e liberdade, as suas ânsias de voar. Está, de novo, como a roseira cheia de rosas para serem colhidas. Porém, há tantas borboletas, no caso cruéis, e não doces, que agora "liban", extraem as suas rosas. Tanta gente que a faz sofrer, seja com a falta de amor, a falta de compreensão, a falta de acolhida da sociedade provinciana argentina a uma mulher que pensa, que sente e quer amar, desejar e falar, que as rosas se acabarão por "secas" e não porque foram colhidas. Essas rosas não decorarão os vasos de flores, nem o cabelo das damas, nem o bolso dos paletós dos cavalheiros, mas morrerão no chão, caídas, corrompidas, tristes e secas como a sua alma e o seu coração. Enfim, a vida, ou falta de vida livre lhe maltrata. Nesse contexto, o seu lugar qual pode ser? A morte e a natureza.

Nesse segundo livro, a Alfonsina, antes romântica de La Inquietud del rosal, passa a tornarse, com mais clareza, uma mulher critica de sua sociedade fechada e patriarcal. Uma sociedade na qual as mulheres são consideradas fúteis e são estigmatizadas por chorarem demais. Alfonsina quando fala de suas dores, é terna e feroz, mas quando critica os regimes vigentes de sua época, é magistralmente irônica. Será esse o temperamento esperado da mulher do início do século XX? Vejamos mais a mencionada ironia no poema "Capricho" (STORNI, 1956), ainda de El dulce daño:

Escrútame los ojos sorpréndeme la boca, sujeta entre tus manos esta cabeza loca; dame a beber veneno, el malvado veneno que moja los labios a pesar de ser bueno.

Pero no me preguntes, no me preguntes nada de por qué lloré tanto en la noche pasada; las mujeres lloramos sin saber, porque sí. Es esto de los llantos pasaje baladí.

Bien se ve que tenemos adentro un mar oculto, un mar un poco torpe, ligeramente oculto, que se asoma a los ojos con bastante frecuencia y hasta lo manejamos con una dúctil ciencia.

No preguntes amado, lo debes sospechar: en la noche pasada no estaba quieto el mar. Nada más. Tempestades que las trae y las lleva un viento que nos marca cada vez costa nueva.

Si, vanas mariposas sobre jardin de Enero, nuestro interior es todo sin equilibrio y huero. Luz de cristaleria, fruto de carnaval decorado en escamas de serpientes del mal. Así somos, ¿no es cierto? Ya lo dijo el poeta: deseamos y gustamos la miel en cada copa y en el cerebro habemos un poquito de estopa.

Bien. No, no me preguntes. Torpeza de mujer, capricho, amado mio, capricho debe ser. Oh, déjame que ría. ¿No ves que tarde hermosa? Espinate las manos y córtame una rosa (STORNI, 1956, p. 18). 
No poema, a promessa da poesia feminina argentina não é individual, senão social. Ela não fala apenas de si, mas das mulheres que, como ela, são cúmplices dos pesares impostos pelo patriarcado latino-americano que as considera seres fracos, que têm "estopa en el cerebro", ou que têm o "interior vacio" e um "mar oculto" por dentro que lhes "sube", sem motivos "a los ojos". Portanto, nota-se que em "Capricho" a voz de Alfonsina passa a não ser mais a voz de um "eu", mas a de um "nós", posto que não é apenas ela que chora, mas todas as mulheres, que com ela compartilham da incompreensão e da culpa. No poema em questão, a poeta fala ao suposto ser amado de uma forma extremamente crítica e irônica sobre os estigmas que sofre a mulher do início dos anos mil e novecentos, e que até hoje, após os movimentos feministas que ganharam força a partir dos anos 1960, ainda estão presentes. De acordo com os preceitos da sociedade patriarcal, Alfonsina denuncia que a mulher é vista como lerda, como diz Erasmo de Rotterdam: "La mujer siempre será mujer, es decir, estulta, aunque se ponga máscara de persona" (2004, p. 55).

Conforme tais ideias deterministas, preconceituosas e conservadoras, presentes na Argentina da época segundo Vasallo e Calle (2014), e expostas criticamente por Storni, a mulher não tem equilibrio e o seu interior é "huero", ou seja, vazio. Porém, apesar de vazia, essa mulher consegue ser a "serpiente" do mal que deve ser "ESCRUTADA", com maiúsculas, isto é, analisada - já que é traidora - pelo homem; o "bom", o "inteligente", o "perfeito" e, sobretudo, o "equilibrado". Aquele que não chora, que não traz o "mar oculto" ou que talvez o traga ainda mais oculto que não deixa que the chegue aos olhos.

Alfonsina encerra o poema ao apresentar a imagem conhecida, a imagem estigmatizada da mulher, a imagem que aquele homem quer daquela mulher: a mulher que é fútil, que quer rosas para se enfeitar e que não as pode cortar com as suas próprias mãos que são "delicadas" demais. O homem, então, sentindo-se viril, valente e poderoso, deve, segundo o senso comum da sociedade patriarcal, "espinarse las manos" e mostrar à mulher a sua força, dando-lhe o que quer. O homem, assim, coloca-se como uma ponte entre a mulher e o mundo.

De igual maneira, é também crítico e irônico o poema "Tú me quieres blanca" (STORNI, 1956), um dos poemas mais conhecidos de Alfonsina, ainde de El dulce daño. Tal poema, como veremos, dialoga e retoma com o poema "Hombres Necios que acusáis" (DE LA CRUZ, [16-?], de Soror Juana Inés de la $\mathrm{Cruz}^{5}$, ao se dirigir diretamente a um homem questionando a sua condição de exigir um comportamento da mulher ao qual ele mesmo não segue. Quer dizer, Alfonsina nesse poema, não apenas fala com voz própria, mas faz reverberar outra mulher pioneira na escrita, Soror Juana Inés de la Cruz, fazendo ver que a luta por direitos já possui uma longa caminhada. Vejamos o poema de Storni:

Tú me quieres alba,

Me quieres de espumas,

Me quieres de nácar.

Que sea azucena

Sobre todas, casta.

De perfume tenue.

Corola cerrada

Ni un rayo de luna

Filtrado me haya.

Ni una margarita

Se diga mi hermana.

Tú me quieres nivea,

Tú me quieres blanca,

Tú me quieres alba.

Tú que hubiste todas

Las copas a mano,

De frutos y mieles

Los labios morados.

Tú que en el banquete

No poema em questão, datado da época do Barroco, Soror Juana Inés de la Cruz reivindica a igualdade social entre homens e mutheres e acusando àqueles de serem hipócritas, já que criticam tanto a mulher que se submete aos seus desejos sexuais quanto aquela que é recatada e que os ignora. Quer dizer, na visão do homem, ao qual cabem todos os direitos, a mulher sempre está fadada ao erro, à crítica, aos olhos que escrutam e que condenam. 
Cubierto de pámpanos

Dejaste las carnes

Festejando a Baco.

Tú que en los jardines

Negros del Engaño

Vestido de rojo

Corriste al Estrago.

Tú que el esqueleto

Conservas intacto

No sé todavía

Por cuáles milagros,

Me pretendes blanca

(Dios te lo perdone),

Me pretendes casta

(Dios te lo perdone),

iMe pretendes alba!

Huye hacia los bosques,

Vete a la montaña:

Limpiate la boca;

Vive en las cabañas;

Toca con las manos

La tierra mojada;

Alimenta el cuerpo

Con raíz amarga;

Bebe de las rocas:

Duerme sobre escarcha;

Renueva tejidos

Con salitre y agua;

Habla con los pájaros

Y lévate al alba.

Y cuando las carnes

Te sean tornadas,

$Y$ cuando hayas puesto

En ellas el alma

Que por las alcobas

Se quedó enredada,

Entonces, buen hombre,

Preténdeme blanca,

Preténdeme nívea,

Preténdeme casta (STORNI, 1956, p. 30).

No poema, ao mesmo passo que interroga o homem, a poeta mostra-lhe todas as suas contradições, as suas "falhas" que, diferentemente do que ocorre com a mulher, são admitidas e até justificadas pela sociedade patriarcal em que vivem. Portanto, em "Tú me quieres blanca" testemunhamos um desabafo da poeta que se dirige a um comportamento castrador masculino - ou de uma sociedade encabeçada pelo homem ou por sua visão limitante, limitada e limitadora que se pretende universal. Essa sociedade que julga a mulher é quadrada e nela não há espaço para aquela que não é "pura", não é "blanca", não é virgem. Como vimos na seção anterior, para dar voz a injustiças cometidas contra as mulheres, a poeta fala com propriedade de causa, pois ela mesma sentiu o rechaço da sociedade ao ser uma mulher independente, mãe solteira e trabalhadora, no primeiro quarto do século XX no sul da América Latina. Isto é, Storni, como a mulher que não é casta, sofreu na própria carne dessa mesma inquisição da sociedade inquisidora que denuncia no poema. Assim, entende-se neste estudo que em razão disso, do empirismo da poeta, o poema não se constrói com um "nós", mas assume um "eu". Contudo, esse "eu" não é apenas Alfonsina, mas qualquer mulher que vivencia a falta de liberdade e de igualdade de gênero nos idos de 1900. Por outro lado, o "tu", com quem dialoga, não é apenas o homem, mas se alinha com todo o comportamento opressor em relação à mulher manifestado pela sociedade da época. Assim, para chamar atenção para essa causa, tão sua e, mas também tão de todas as mulheres, a poeta ironiza a posição privilegiada do homem, chamando-o de "buen hombre". Esse homem, que é "bom" aos olhos da sociedade patriarcal, não é casto, não é puro, entretanto, exige que a mulher o seja. Logo, ao se dirigir ao "buen hombre" nos últimos versos, a poeta põe em xeque o significado de "bueno" para a sociedade. Isto é, a como mulher que não tem "corola cerrada" não é considerada "buena", mas o homem que rompe a sua corola, que "corre al estrago", pode ser "bom"? Não seria uma contradição?

A castidade, por sua vez, está representada no poema pelas imagens "blanca", "alba" e principalmente pela flor "azucena". Para ser "boa", 
a mulher deve, então, ser uma flor de corola fechada, porém, não qualquer flor, mas a açucena, simbolo da pureza (CIRLOT, 1992, p. 926). Enquanto isso o homem pode se vestir de "rojo", vermelho, cor do desejo, da paixão e, mesmo estando de vermelho, festejando a "Baco", fazendo o "estrago", ainda assim ele é "bom" aos olhos da sociedade. Não obstante, no final do poema, Alfonsina esclarece que este homem "bom" para essa sociedade em que vive, não é bom para Deus. Diz ela que Deus tem que "perdonar" o homem que acredita não ter culpas. Logo, a poeta entende que Deus não é preconceituoso e nem hipócrita como é a sociedade do começo do século XX, da qual ela fazia parte.

No livro El dulce daño, portanto, é possivel perceber que tanto o homem como a sociedade e a cidade fria de Buenos Aires, onde vive Alfonsina, parecem pesar sobre a poeta. Para ela, a carga desse peso de desigualdades é dura e, com sede de autonomia, ela pede "Agua":

iAgua, agua, agua!

Eso voy gritando por calles y plazas.

iAgua, agua, agua!

No quiero beberla,

no quiero tomarla,

no es la boca mía la que pide agua.

El alma de seca, de seca

se rasga.

Por eso me lanzo por calles y plazas

pidiendo a destajo:

iAgua, agua, agua!

Abridme las venas,

vertedles la clara corriente de un rio.

iAgua, agua, agua! (STORNI, 1956, p. 31).

Acima, Alfonsina nos revela que a sua alma está seca da "não compreensão", do "não respeito", da "não tolerância", do "não amor", da "não liberdade", que lhe outorgam a cidade, que é fria, e o homem, que é hipócrita. A dor que ela sente não é física e a água que ela pede não é para a sua garganta, senão para a sua "alma", já que a sua ferida é interna. Cansada de esperar a compreensão, a aprovação da cidade grande, porém fria, que não the trouxe o alento esperado, Alfonsina - negando a sua aparência frágil - evidencia querer ser livre, querer viver a sua liberdade como demonstra em outro poema do mesmo livro, intitulado "¿Qué diria?" (STORNI, 1956)
¿Qué diría la gente, recortada y vacia,
si un día fortuito, por ultra fantasía,
me tiñera el cabello de plateado y violeta,
usara pelo griego, cambiara la peineta
por cintillo de flores: miosotis o jazmines,
cantara por las calles al compás de violines,
o dijera mi verso recorriendo las plazas
libertado mi gusto de mortales mordazas?
¿Irian a mirarme temblando en las aceras?
¿Me quemarían como quemaron hechiceras?
¿Rogarian en coro, escuchando la misa?
En verdad que pensarlo me da un poco de risa (STORNI, 1956, p. 33).

A cidade, de aço, ao contrário da natureza, que é mãe e nutriz, é "falsa", "recortada" e "vacia", artificial. Essa cidade, apesar de grande, não tolera na mulher o direito à fantasia, que não é nada mais do que fazer as coisas que são permitidas e até admiradas nos homens, a saber: querer e poder recitar "versos en la calle"; "cantar al compás de violines"; não ter "mordazas". Para a mulher, ou para as mulheres, isso era rechaçado, e caso o fizessem, seriam vistas como "feiticeiras" e condenadas pelo simples fato de fazerem o que têm vontade, já que a mulher livre é entendida pela sociedade patriarcal como "má", "bruxa", "falsa", ou seja, o próprio demônio. O provincianismo da gente da cidade grande, ao fim do poema, chega a ser, para a poeta, engraçado e a faz rir, posto que ela parece não poder vencêlo. A cidade grande e feroz é feita de aço e de

\footnotetext{
6 "Emblema de la pureza, utilizado en la iconografía cristiana, especialmente en la medieval, como símbolo y atributo de la Virgen María. Con frecuencia aparece erguida en un vaso o jarrón, símbolo a su vez del principio femenino" (CIRLOT, 1992, p. 92).
} 
quadrados e nela não há espaço para a mudança. A cidade dura corrompe até as almas doces como a dos poetas, como Storni nos diz no poema "Cuadrados y ángulos", também de El dulce daño:

Casas enfiladas, casas enfiladas,

Casas enfiladas.

Cuadrados, cuadrados, cuadrados.

Casas enfiladas.

Las gentes ya tienen el alma cuadrada,

Ideas en fila

$Y$ ángulo en la espalda.

Yo misma he vertido ayer una lágrima,

Dios mío, cuadrada (STORNI, 1956, p. 35).

As mentes pequenas, produtos da cidade "cuadrada", marcam "ángulos" inclusive em sua poesia, que dá voz às suas inquietudes. Quer dizer, nesse poema, Alfonsina marca o ritmo duro da cidade por meio da repetição de palavras que propiciam uma leitura áspera, quadrada, reta. As mentes pequenas dos cidadãos da grande cidade integram e fazem rodar essa engrenagem acrítica que move a sociedade patriarcal e estagnada da grande Buenos Aires. As pessoas da metrópole não mudam, não têm ideias e quando as têm, elas vêm em fila. A cidade quadrada de concreto não oportuniza espaços para a criatividade e apenas segue padrões impostos sem questionar de onde eles vieram. Por conseguinte, parece não haver possibilidade de mudança na frieza da metrópole. Até as lágrimas, algo de essência nobre e mágica, são para aquele que vive na selva de "ángulos", "cuadradas". Alfonsina, o ser doce, a filha da natureza, evidencia, então, nesse poema, começar a se corromper pela cidade posto que. inclusive ela, revela derramar, em meio a tantas asperezas, lágrimas doentes, lágrimas angulosas, lágrimas quadradas.

No mesmo tom de denúncia ou de busca de mudança, serão os poemas - "Peso ancestral", "Hombre pequenito", "Veinte siglos" e "Bien pudiera ser" - que fazem parte de Irremediablemente, o seu seguinte livro, publicado em 1919.

Em "Peso ancestral" (STORNI, 1956), a poeta fala ainda mais nitidamente sobre o que é ser mulher, sobre o que é ser homem e carregar o peso atribuido a cada uma dessas duas condições. Diz a poeta que o homem, para ser aceito, tem que ser forte como foram seu avô e seu pai, enquanto a mulher precisa demonstrar ser frágil. Desse modo, ambos devem suportar o peso de seus destinos que carregam, sobre os ombros, séculos de dor. Entretanto, há uma esperança no poema, já que quando o homem revela que tem que ser de aço como os seus ancestrais, brota-lhe uma lágrima e talvez uma semente de mudança venha junto com ela. Sendo assim, percebemos que, apesar de todo o contexto opressivo vivido e revelado pela poeta pelas mulheres da época, ela entende que o homem do século $X X$, quem sabe, possa deixar de ser de aço. Observemos:
Tú me dijiste: no lloró mi padre;
tú me dijiste: no lloró mi abuelo;
no han llorado los hombres de mi raza,
eran de acero.
Asi diciendo te brotó una lágrima y me cayó en la boca... más veneno.
Yo no he bebido nunca en otro vaso asi pequeño
Débil mujer, pobre mujer que entiende dolor de siglos conoci al beberlo: iOh, el alma mía soportar no puede todo su peso! (STORNI, 1956, p. 49).

Já em "Hombre pequenito" (STORNI, 1956), Alfonsina se dirige a outro homem, ao inflexivel, ao que faz questão de ser de aço e que quer prender, submeter, reinar sobre a mulher, privá-la de sua liberdade, extrair-lhe as rosas das mãos ao invés de as colher como já exposto aqui no poema "Este grave daño", analisado anteriormente.

Hombre pequeñito, hombre pequeñito, Suelta a tu canario que quiere volar... Yo soy el canario, hombre pequeñito, déjame saltar.

Estuve en tu jaula, hombre pequeñito, hombre pequeñito que jaula me das. Digo pequeñito porque no me entiendes, ni me entenderás. 
Tampoco te entiendo, pero mientras tanto ábreme la jaula que quiero escapar; hombre pequeñito, te amé media hora, no me pidas más (STORNI, 1956, p. 53).

Esse homem do poema, que é pequeno, de mente pequena, quer privar o "canario", o pássaro cheio de vida, de voar, de sentir. É esse homem o descendente e o integrante de vinte séculos de homens ásperos, de homens que oprimem, que não choram. Para ele não há amor duradouro e, por conseguinte, não deve haver espaço para ele na nova sociedade que ela almeja, que está por vir. A poeta, sedenta de vida, ama esse homem por meia hora apenas, nada mais, pois se dá conta de que ele não sabe amar, e sim possuir. Podemos vislumbrar, por meio do poema em questão, outra confissão de Alfonsina que, ao querer amar, muitas vezes, sentiu-se como em uma gaiola, presa, com suas ânsias e desejos controlados, ofuscados, silenciados. Alfonsina, desde o começo de sua obra, como já analisado, demonstra buscar o amor, porém ela quer também a sua liberdade, um amor que seja liberdade. Uma liberdade de sentir, de viver e de expressar os seus sentimentos, o que não era tolerado a uma mulher "buena". Tais ideias também podem ser achadas igualmente no poema "Veinte siglos" (STORNI, 1956):

Para decirte, amor, que te deseo,

sin los rubores falsos del instinto.

Estuve atada como Prometeo,

pero una tarde me sali del cinto.

Son veinte siglos que movió mi mano

para poder decirte sin rubores:

"Que la luz edifique mis amores".

iSon veinte siglos los que alzo mi mano!

Pasan las flechas sobre mis cabellos, pasan las flechas, aguzados dardos... iSon veinte siglos de terribles fardos! Senti su peso al libertarme de ellos (STORNI, 1956, p. 54).

Nesses versos, a poeta afirma que, para que uma mulher pudesse se expressar, ter voz e poder sentir desejo sem falsos rubores, sem dissimulações, foram necessários "veinte siglos". Não obstante, nem após esse longo tempo de prisão, a mulher que ama é perdoada, já que, no poema, essa mulher vê passarem por si "flechas" que a condenam. Entretanto, a mesma mulher que, como Alfonsina, quer e deseja, ainda que sinta o peso que carregam os seus ombros dos vinte séculos de "silencio", não renuncia à sua voz e à sua liberdade e segue desejando, ainda que isso the custe a paz. Desse modo, o poema termina quando a mão dessa mulher, por que não de Alfonsina, levanta-se contra os vinte séculos de opressão.

Novamente, em "Bien pudiera ser" (STORNI, 1956), temos outra espécie de confissão de Alfonsina, isto é, ela explica como nascem e o que significam para ela os seus versos. Diz a poeta que esses the escapam como uma fonte que jorra água, como um mar que invade, como uma roseira que floresce, como una voz que, ao contrário da de sua mãe e das demais mulheres que sofreram os vinte séculos de opressão, não quer e não se pode calar.

\footnotetext{
Bien pudiera ser que todo lo que en verso he sentido

no fuera más que aquello que nunca pudo ser, no fuera más que algo vedado y reprimido de familia en familia, de mujer en mujer.

Dicen que en los solares de mi gente, medido estaba todo aquello que se debía hacer...

Dicen que silenciosas las mujeres han sido de mi casa materna... Ah, bien pudiera ser...

A veces en mi madre apuntaron antojos de liberarse, pero, se le subió a los ojos una honda amargura, y en la sombra lloró.

Y todo esto mordiente, vencido, mutilado, todo esto que se hallaba en su alma encerrado, pienso que sin quererlo lo he libertado yo (STORNI, 1956, p. 62).
}

Storni, em seus escritos, desnuda os seus silêncios, ou melhor, os silêncios do âmbito do "somos", isto é, os pesares comuns de "mujer en mujer". A poeta denuncia que tudo para a mulher é "medido", que para elas não há espaço para a 
liberdade de expressão e que por isso, muitas tiveram que ser "silenciosas". Ainda que sua mãe, ou qualquer das mulheres caladas, tivesse "antojos", (desejos não racionais), jamais pôde/ puderam concretizá-los e os calou/calaram. A quem coube a tarefa de pô-los para fora? A ela, a poeta, a mulher que fala por seus poemas, pelas demais e que derrama no papel todo o peso que se acumula nas almas das emudecidas. Almas essas que não comportam aquilo que o corpo regula. A poesia, para Alfonsina é, então, o dia de ressaca de um mar cruel, um mar que lava, que espalha os seus domínios e que se renova ao sabor das ondas. Alfonsina é o próprio mar ${ }^{7}$ e as suas ondas são as palavras.

Para Alfonsina, Irremediablemente não era um bom livro e confessa (no fim da edição) que o escreveu em dois meses, entre janeiro e fevereiro de 1919, em um momento de grande desgosto. Porém, as imagens que a obra traz pertencem, sem dúvida, à poeta que se mostra, ali, transparente. Quando escreve Irremediablemente, Alfonsina está em uma situação de efervescência. Já é reconhecida como a maior poeta feminina da Argentina, é professora, ministrando aulas de Literatura e declamação em institutos privados, e tem uma seção semanal na revista La Nota. Na mesma época, começa a escrever um drama, La mujer piedra, e dois volumes de versos, Paganas e El poema fresco, mas nenhuma dessas três obras foi divulgada ao grande público.

O livro que seguiu à Irremediablemente foi Languidez, que saiu à luz em 1920 e lhe trouxe o reconhecimento do público com o seu primeiro prêmio de poesia. Languidez lhe dá o primeiro prêmio municipale o segundo nacional de poesia. Os prêmios a deixam ainda mais reconhecida, e a fama a leva a Montevidéu onde faz conferências ${ }^{8}$ sobre Delmira Agustini, poeta uruguaia contemporânea, que na época já havia publicado três livros. Nesse periodo, o entusiasmo com Alfonsina pela América Hispânica crescia e muitos a chamavam de poeta mais completa do continente. Comentava-se muito sobre a sua vastíssima erudição, a qual, segundo Helena Percas (1958), não possuía e compensava com a sua inteligência inata e com a sua forte personalidade que se escondia sob um esqueleto frágil e nervoso. Diz a própria Alfonsina sobre si mesma em uma carta que escreve a seu amigo Julio Cejador em 1917: "Todo lo que he hecho hasta ahora es... obra de mi propio instinto más que de mi cultura, que no he tenido tiempo ni calma para ensanchar a mi gusto" (STORNI, 1917 apud PERCAS, 1958, p. 92). Já sobre Languidez a escritora comenta:

\begin{abstract}
Este libro cierra una modalidad mía. Si la vida y las cosas me lo permiten otra ha de ser mi poesia mañana. Inicia en este conjunto, en parte, el abandono de la poesía subjetiva que no puede ser continuada cuando un alma ha dicho respecto de ella, todo lo que tenía que decir, por lo menos en un sentido. Tiempo y tranquilidad me han faltado hasta hoy para desprenderme de mis angustias y ver así lo que está a mi alrededor. Pero, si continúo escribiendo, he de procurarme el tiempo y la tranquilidad que para ello me harán falta (STORNI, 1920 apud OROSCO, 1940, p. 258).
\end{abstract}

E dedica a obra àqueles que, como ela, não realizaram nem um só de seus sonhos. Apesar da maturidade de sua obra, Languidez segue trazendo temas recorrentes, mostrando uma poeta ainda mais melancólica e desiludida. No poema "El Clamor", de Languidez, (STORNI, 1956), ela novamente fala dos riscos e das dores de, como mulher, sentir e se entregar.

Alguna vez, andando por la vida, por piedad, por amor, como se da una fuente, sin reservas, yo di mi corazón.

Y dije al que pasaba, sin malicia, y quizá con fervor: - Obedezco a la ley que nos gobierna: He dado el corazón.

Y tan pronto lo dije, como un eco ya se corrió la voz:

-Ved la mala mujer esa que pasa: Ha dado el corazón.

De boca en boca, sobre los tejados, rodaba este clamor:

\footnotetext{
Para entender melhor sobre a relação metafórica entre Alfonsina Storni e o mar, aconselha-se a leitura de Retamar (2004; 2006)

8 Dita conferência aconteceu em 1920 na universidade uruguaia.
} 
-iEchadle piedras, eh, sobre la cara;

ha dado el corazón!

Ya está sangrando, sí, la cara mía, pero no de rubor,

que me vuelvo a los hombres y repito:

iHe dado el corazón! (STORNI, 1956, p. 88).

Nesse poema, a poeta reitera a seus leitores a quais leis o seu ser está submetido. Não às leis dos homens, mas as da sensibilidade. Os homens, entendidos no poema, outra vez, como a sociedade patriarcal e opressora, são cruéis, pequenos e mesquinhos, posto que não outorgam à mulher o direito de se entregar. A mulher que quebra essa regra é, então, vista como má e merece a ira da sociedade nessa cruel e injusta lei dos homens. Já aquela mulher que é ativa, que não se submete, que age conforme o seu livre-arbítrio, que segue as regras de sua mãe natureza, sofre e recebe o maltrato e a injúria. Para essa mulher, a vida é dor e a morte é liberdade.

De igual forma, em "La armadura" (STORNI, 1956), a poeta reforça a ideia de que para a sociedade a mulher deve ser submissa. Contudo, ao mesmo tempo que diz isso, ela convoca às mulheres à revolução, instigando a que todas se olhem nos olhos e que se sintam dignas da vida plena, como filhas da natureza que são.

MUJER: tú la virtuosa, y tú la cínica,

Y tú la indiferente o la perversa;

Mirémonos sin miedo y a los ojos:

Nos conocemos bien. Vamos a cuentas.

Bajo armadura andamos: si nos sobra

El alma, la cortamos; si nos llenas,

Por mengua, la armadura, pues la henchimos:

Con la armadura andamos siempre a cuestas.

iArmadura feroz! Mas conservadla.

Si algún dia destruirla pretendierais,

Del solo esfuerzo de arrojarla lejos

Os quedariais como yo, bien muertas (STORNI, 1956, p. 94).
Ao escrever "MUJER" com maiúsculas, Storni chama a todas, as "cínicas" e as "virtuosas", as "perversas", porque ainda que diversas, elas compartilham da mesma dor que é ser do sexo feminino, o "segundo sexo" (NAVARRO, 1995, p. 16) e não poder sê-lo em sua totalidade. A poeta conclama as mulheres a se libertarem de seus medos e a enfrentarem a vida, a abandonarem a armadura que vestem, a se livrarem do silêncio e se vestirem de vida, de voz, insurgindo contra o que Landy (1977, p. 19) chama de "mito da mulher silenciosa"9. Porém, quando termina o clamor, a mulher, que parecia corajosa e convencida da sua necessidade de lutar, retrocede os seus passos, já que reconhece que, no mundo em que vive, tal armadura se faz necessária, porque com ela a vida é limitada, mas sem ela é inexistente. A poeta, entretanto, assume ter abandonado a sua armadura e confessa que, em vez da vida desejada por sua alma de mar e roseira inquieta, recebeu de troco o preconceito e a morte em vida.

As poesias posteriores de Alfonsina seguem contendo a subjetividade já característica, ainda que ela já não a quisesse e pretendesse mudar os rumos de sua escrita. Em 1925, é publicado seu livro Ocre. Em 1934, Mundo de Siete Pozos e em 1938, ano de sua morte, publica Mascarilla y Trébol e organiza, ela mesma, a Antología Poética (1956) de sua obra, de onde foram extraídos os poemas aqui analisados. Alfonsina Storni, a poeta da alma e da procura, não se limitou ao terreno da poesia, escrevendo também contos e peças de teatro, por mais que os últimos não tivessem uma boa recepção por parte do público.

Ao longo desta análise, houve o objetivo de demostrar que a voz que rompeu o silêncio imposto à mulher latino-americana no início do século XX, perdura até hoje, época em que, apesar do tempo transcorrido e dos movimentos feministas que ganharam força a partir dos anos 1960 (bem posteriores à morte de Alfonsina), a mulher ainda não ocupa o seu espaço em igualdade de condições com os homens.

Sendo assim, Alfonsina é entendida aqui como

\footnotetext{
9 "Women who have been segregated and powerless, had not full access to language, and have not had access to the larger Society beyond the domestic arena have continued to fulfill the myth of the silente woman in one form or another" (LANDY, 1977, p. 19).
} 
uma das pioneiras combatentes pela igualdade de gênero, travando a sua luta por meio de sua palavra imperecivel que cruzou as fronteiras do tempo e do espaço. Assim, tenho acordo com Rocha (2012, p. 198), que diz que "en los poemas en prosa de Alfonsina Storni no hay solamente una posición-sujeto femenino formado por un cuerpo-amoroso-erótico, sino también, y principalmente, por un cuerpo-social que se instaura en la diferencia y en el distanciamiento", já que, como vimos, Alfonsina, em seu tempo, ousou fazer uma poesia engajada, ainda que subjetiva. Contudo, apesar da subjetividade, e talvez por ela, haja com maior força uma contextualização sociocultural dos pesares e agruras não apenas dela, mas de um "nós", ou seja, das mulheres que com ela compartilharam, e ainda compartilham, os reveses da desigualdade. Ao lutar por meio de seus versos, a poeta reconheceu ferir-se, mas plantou sementes que germinam ainda hoje, principalmente, se pensamos na cada vez mais massiva presença de autoras latinoamericanas que surgem a partir dos anos $1960 \mathrm{e}$ que também reivindicam a história e o espaço das mulheres, tanto tempo silenciadas na sociedade. Portanto, entende-se aqui que ler Alfonsina é sensibilizar-se e também é entender e reivindicar uma luta de séculos. Divulgar a sua obra, por sua vez, é dar continuidade a essa luta e ao desejo de uma sociedade mais igualitária e menos angulosa, onde cada qual possa ser livre e viver intensamente sem medo de sofrer com as flechas inquisidoras do preconceito e da intolerância.

\section{Considerações finais: o legado da voz poderosa de Alfonsina}

Pelo recorte feito ao longo desta análise, este estudo compreende Alfonsina como a mulher que quer se libertar de todas as armaduras, de todos os silêncios, de todos os preconceitos. Como vimos por meio de seus poemas aqui analisados, ela denuncia tudo aquilo que a fere e que a corrompe, e busca o amor, um amor ideal como a natureza, o amor-natura ${ }^{10}$.

Contudo, essa voz sedenta de mudanças, cala-se, parcialmente, em 1938, quando a poeta, cansada do peso da vida que a maltrata, descobrese doente de um câncer no seio, motivo pelo qual muitos atribuem a razão de sua morte. Porém, será que uma alma como a de Alfonsina, a menina que inventava histórias aos professores, a mulher que dominava os saraus poéticos com a magia e a sabedoria de suas palavras, a poeta que foi considerada a mais completa da América Hispânica, aquela que lutava com a caneta contra a sociedade quadrada, aquela com o coração que buscava o amor desesperadamente, aquela se via como uma roseira que florescia inquieta, enfim, a ansiosa de liberdade e sedenta de vida se suicidaria ao entrar no mar em razão de um câncer?

Creio que considerar esse o motivo de sua morte é tornar banal a obra e a vida de quem tanto sentia e desejava. Não esqueçamos de que, como dito na primeira seção deste estudo, a ideia da morte estava presente na obra da poeta desde a sua adolescência, quando não se imaginava doente. Para ela, a morte, era sinônimo de mudança e não de fim e estava sempre espreitando-a e desejando-a, chamando-a bem como a força da natureza, a força do mar que a reclamou. Não esqueçamos que a poeta tinha uma alma fantástica, como ela mesma dirá em seu poema "Palabras a mi madre" (STORNI, 1956), e para essas almas, que vivem e se alimentam de sonhos, não há um final ou um simples adeus como para os mortais. Alfonsina, com seus versos e suas atitudes, não apenas transgrediu uma sociedade patriarcal e desafiou a cidade e o homem opressivos, mas os venceu ao semear palavras propulsoras de mudança.

Ao se suicidar entrando no mar, em 1938, a poeta tornou-se mito ${ }^{11}$ por cumprir com as profecias já presentes em longa data em seus versos. A mulher da aparência frágil e das ideias libertadoras que se lançou ao mar e se eternizou, revolucionou a escrita feminina da Argentina com seus versos de rosas, de espinhos, de sal, de mar às vezes doce e

\footnotetext{
Referência ao poema "Un Sol", de Irremediablemente (STORNI, 1956, p. 57).

Recordo aqui a canção que narra a morte mítica da poeta, "Alfonsina y el mar", de autoria de Félix Luna e Ariel Ramírez, que foi eter-
} nizada na voz de Mercedes Sosa. 
tranquilo; outras arrebatador e violento. Portanto, Alfonsina foi, mas ainda é, posto que seus versos são imortais, a mulher que sofreu o peso de seu século. Sua força foi a sua alma e a sua arma, foi a palavra escrita, a palavra duradoura que chegou a nossos dias e que, até hoje, é necessária na busca pela igualdade de gêneros, ainda não alcançada em pleno século XXI.

Sendo assim, o presente estudo entende que a recuperação e o compartilhamento da obra de Storni faz-se fundamental para os estudos contemporâneos não apenas sobre poesia, mas sobre a relação entre o feminino a história, a literatura e a sociedade do século XX. Chega-se a essa conclusão por reconhecer não apenas a riqueza poética da obra de Alfonsina, mas por valorizar a audácia de suas palavras que promovem, em uma época ainda mais castradora que a atual para o feminino, um olhar crítico e propulsor de mudanças sociais em favor da igualdade, tão necessária, entre homens e mulheres.

\section{Referências}

CIRLOT, Juan Eduardo. Diccionario de simbolos. Barcelona: Labor, 1992.

ETCHENIQUE, Nira. Alfonsina Storni. Buenos Aires: La Mandrágora, 1958.

GIORDANO, Verónica. Vida, obra y muerte de Alfonsina Storni, Delmira Agustini y Ercilia Cobra: la construcción de los derechos civiles. Cadernos Pagu, Campinas, n.32, p.331-364, Jan./Jun. 2009. Disponivel em: https://doi.org/10.1590/s010483332009000100011 Acesso em: 15 jun. 2018.

LANDY, Marcia. The silente woman: towards a feminist critique. In: DIAMOND, Arlyn; EDWARDS, Lee (org.). The authority of experience: essays on feminist criticism. Amhrest: The University of Massachusetts Press, 1977. p. 16-27.

DE LA CRUZ, Sor Juana Inés [s.d]. Hombres necios que acusáis. Obras Clássicas de siempre: redondillas. Disponivel em: http://bibliotecadigital.ilce.edu.mx/Colecciones/ObrasClasicas/_docs/Redondillas.pdf Acesso em: 15 jun. 2018. https://doi.org/10.2307/j.ctv5131bv.6

NAVARRO, Márcia Hoppe. Por uma voz autônoma: o papel da mulher na história e na ficção latino-americana contemporânea. In: NAVARRO, Márcia Hoppe (org.). Rompendo o silêncio: gênero e Literatura na América Latina. Porto Alegre: Editora da Universidade Federal do Rio Grande do Sul, 1995. p. 11-55. https://doi.org/10.29289/259453942018v28s1059
OROSCO, María Teresa. Alfonsina Storni. Buenos Aires: Imprenta de la Universidad, 1940. (Facultad de Filosofia y Letras de la Universidad de Buenos Aires, Instituto de Literatura Argentina, Sección de Critica, V. II, n. 4). https://doi.org/10.20319/piiss.2017.32.20152033

PERCAS, Helena. La poesia femenina argentina. Madrid: Ediciones Cultura Hispánica, 1958.

RETAMAR, Hugo Jesús Correa. Alfonsina y su mar. 2004. 72f. Monografia (Licenciatura em Letras) - Universidade Federal do Rio Grande do Sul, Porto Alegre, 2004. https://doi.org/10.29289/ 259453942018v28s1059

RETAMAR, Hugo Jesús Correa. Alfonsina Storni, Laura Restrepo e a palavra-arma, Cadernos do IL, Porto Alegre, n. 32, p. 73-82, jun. 2006.

ROCHA, Nidicéia Aparecida. Discursividad social del texto femenino: el discurso literario aceptable. Gramma, Salvador, n. 4, p. 194-199, 2012.

ROTTERDAM, Erasmo de. Elogio de la Locura. Madrid: Ediciones Mestas, 2004

STORNI, Alfonsina. Antología Poética. Buenos Aires: Losada, 1956.

VASALLO, Jaqueline; CALLE, Leandro. Alfonsina Storni: literatura y feminismo en la Argentina de los años 20. Rosario: EDUVIM, 2014

\section{Endereço para correspondência}

Hugo Jesús Correa Retamar

Universidade Federal do Rio Grande do Sul

Av. Bento Gonçalves, 9500, prédio 43815, Sala 224

Bairro Agronomia 91509-900

Porto Alegre, RS, Brasil

\section{Hugo Jesús Correa Retamar}

Doutor em Linguística Aplicada (UFRGS), Mestre em Literaturas Estrangeiras Modernas (UFRGS) e professor efetivo, desde 2011, do Colégio de Aplicação da Universidade Federal do Rio Grande do Sul. Atua desde 2002 como professor de espanhol e literatura, já havendo trabalhado no Instituto de Letras da UFRGS (como professor substituto de espanhol e literatura), no Colégio Farroupilha e no Instituto Cervantes de Porto Alegre. Atualmente é lider do grupo de pesquisa LEISA (Língua Espanhola e Interação de Sala de Aula). 